\title{
Targeting focal adhesion kinase in ER + /HER2 + breast cancer improves trastuzumab response
}

\author{
Glorianne Lazaro, Chris Smith, Lindy Goddard, Nicola Jordan, Richard McClelland, \\ Peter Barrett-Lee ${ }^{1}$, Robert I Nicholson and Stephen Hiscox
}

School of Pharmacy and Pharmaceutical Sciences, Cardiff University, Redwood Building, Cardiff, Wales CF10 3NB, UK ${ }^{1}$ Velindre Cancer Centre, Velindre Hospital, Whitchurch, Cardiff, UK
Correspondence should be addressed to S Hiscox

Email

Hiscoxse1@cf.ac.uk

\begin{abstract}
The HER2 transmembrane receptor is a well-characterised predictive marker for trastuzumab benefit and may be associated with decreased benefit from endocrine therapy use. Despite the clinical effectiveness of anti-HER2 agents in such cases, resistance represents a significant limiting factor. Focal adhesion kinase (FAK) plays an important role in HER2 signalling, mediating downstream Akt activation in addition to HER2 cross talk with other growth factor receptors. In this study, we investigated the therapeutic potential of FAK in oestrogen receptor-positive $(E R+) / H E R 2+$ breast cancer using the novel FAK-specific inhibitor PF4554878 ('PF878'). The activation of the FAK/HER2 signalling pathway was assessed in ER +/HER2 - (MCF7 and T47D) and ER +/HER2 + (BT-474 and MDAMB361) breast cancer cells in the presence or absence of PF878 and PF878 \pm trastuzumab. The effects of PF878 on cell growth as a monotherapy and in combination with trastuzumab were assessed using 3-(4,5-dimethylthiazol-2-yl)-2,5-diphenyltetrazolium bromide and Coulter counting with isobologram analysis to determine synergy/additive effects. FAK activation (at Y861 but not at Y397) was highest in ER +/HER2 + cells, which also demonstrated the greatest sensitivity to PF878. As a monotherapy, PF878 prevented heregulin-induced MDA361 cell migration, but had no significant effect on cell growth. The treatment of ER +/HER2 + cells with PF878 and trastuzumab in combination resulted in the synergistic inhibition of cell proliferation. Underlying this was an abrogation of Akt activity and increased poly(ADP-ribose) polymerase cleavage, effects that were greatest in trastuzumab-refractory MDA361 cells. Collectively, these data support a role for FAK in ER +/HER2 + breast cancer, where its targeting has the potential to improve trastuzumab response. This is particularly important in the context of ER+/HER2 + , trastuzumab-refractory disease, where FAK inhibition may present an important strategy to restore trastuzumab sensitivity.
\end{abstract}
Key Words
- focal adhesion kinase
- human epidermal growth factor receptor 2
- HER2
- luminal B breast cancer
- trastuzumab
- breast cancer

Endocrine-Related Cancer (2013) 20, 691-704

\section{Introduction}

Molecular and biological profiling has identified a subset of oestrogen receptor-positive $(\mathrm{ER}+)$ luminal breast cancers that co-expresses the epidermal growth factor receptor 2 (ERBB2/'HER2') protein (Guiu et al. 2012).
HER2 expression in ER + breast cancers characterises a dominant form of the 'luminal B' molecular subtype and, compared with ER+/HER2 - (luminal A) tumours, these tumours tend to exhibit reduced disease-free survival 
(Ishitobi et al. 2013) or increased recurrence rates (Millar et al. 2009) and an approximately twofold increased adjusted risk of breast cancer mortality (Haque et al. 2012).

The presence of HER2 in ER + breast cancers directs for treatment using agents targeted against the HER2 receptor. Trastuzumab (Herceptin, Genentech, South San Francisco, CA, USA), a humanised MAB directed against the extracellular domain of HER2 (Carter et al. 1992), has been shown to selectively exert anti-tumour effects in cancer models and patients with HER2-enriched breast cancer (Vogel et al. 2002, Romond et al. 2005). Despite the clinical effectiveness of trastuzumab in the treatment of HER2 + tumours, intrinsic or secondary resistance to trastuzumab represents a significant hurdle (Arribas et al. 2011), highlighting the importance of developing new therapies for this disease.

Focal adhesion kinase (FAK) is an intracellular kinase localised to focal adhesions and undergoes integrindependent tyrosine phosphorylation. FAK controls a number of cellular functions such as cell migration and invasion through its ability to regulate cytoskeletal function. More recently, FAK has been shown to regulate epithelial-to-mesenchymal transitions through the modulation of cell-cell junction integrity (Cicchini et al. 2008). Consequently, FAK activation has been shown to contribute to the malignant phenotype of breast cancer cells and is associated with invasive breast tumours (Lin et al. 2005).

FAK represents a link between integrin and receptor tyrosine kinases, including the erbB family, acting as a scaffold that interacts with and integrates both these elements to promote their clustering and activity within the membrane. FAK additionally serves as a key effector for erbB receptors, with the EGF being unable to phosphorylate the EGFR and promote migration in cells lacking FAK (Sieg et al. 2000), while heregulin/HER2 stimulation results in altered FAK phosphorylation and modification of focal contacts and cell-matrix adhesion (Vadlamudi et al. 2003). Moreover, FAK is key to the transduction of HER2 signalling in HER2-overexpressing MCF10A breast cells (Wang et al. 2005) and in MUC4-overexpressing ovarian cancer cells, which have elevated HER2 activity (Ponnusamy et al. 2008). FAK has been reported to be of prognostic significance in lung and oesophageal tumours (Itoh et al. 2004), and in breast cancer, levels of FAK (PTK2) expression correlate strongly with poor tumour differentiation and are significantly associated with HER2 overexpression (Schmitz et al. 2005). Interestingly, in tumours expressing HER2, the levels of FAK phosphorylation also appear to be significantly greater.

Given that intrinsic hyperactivation (Berns et al. 2007) and/or trastuzumab-induced activation of alternative signalling pathways (Lee-Hoeflich et al. 2008) have been shown to mediate trastuzumab resistance and that FAK acts as a downstream effector of HER2 signalling, we investigated whether FAK contributes to the limitation of trastuzumab response in ER +/HER $2+$ breast cancer. We showed that the inhibition of FAK activity in cell models of ER + /HER2 + breast cancer augments their response to trastuzumab and is accompanied by an enhanced suppression of Akt signalling and increased apoptosis. Our data point to the potential of FAK as a novel therapeutic target in ER +/HER2 + breast cancer through which response to the existing HER2-targeted agents might be improved.

\section{Materials and methods}

\section{Reagents}

The FAK-selective inhibitor PF4554878 ('PF878' (Infante et al. 2012)) was provided by Pfizer (Sandwich, Kent, UK). Stock solutions of PF878 were dissolved in DMSO prior to dilution in tissue culture medium at the concentrations indicated. Antibodies used were as follows: anti-FAK (total and Y397), Src kinase (Y419) and Akt (Ser 473), which were obtained from Invitrogen, and anti-HER2 (Y1121 and total) and anti-ERK1/2 (S202/T204 and total), which were obtained from Cell Signalling Technology (New England Biolabs, Herts, UK). All other reagents were obtained from Sigma, unless otherwise stated.

\section{Cell lines and cell culture}

Two human breast carcinoma cell lines that constitutively overexpress HER2 because of the amplification of the HER2 gene (BT-474 and MDA-MB-361 (Hynes et al. 1989)) and two human breast carcinoma cells that lack HER2 overexpression (MCF7 and T47D) were obtained from the American Type Culture Collection (ATCC, Middlesex, UK). All the four cell lines were routinely cultured in RPMI medium (Invitrogen) supplemented with 5\% FCS, $10 \mathrm{IU} / \mathrm{ml}$ penicillin, $10 \mu \mathrm{g} / \mathrm{ml}$ streptomycin, $2.5 \mu \mathrm{g} / \mathrm{ml}$ fungizone and $200 \mathrm{mM}$ glutamine. In all the experiments, the tissue culture medium ( \pm treatments as indicated) was replaced every 3 days, unless otherwise stated.

\section{Cell proliferation assays}

3-(4,5-Dimethylthiazol-2-yl)-2,5-diphenyltetrazolium bromide cell viability assay Changes in cell number in response to treatment exposure were determined by measuring mitochondrial conversion of

Published by Bioscientifica Ltd. 
the formazan reagent (3-(4,5-dimethylthiazol-2-yl)-2,5diphenyltetrazolium bromide (MTT)) as follows: the cells were seeded into 96 -well plates at $6 \times 10^{3}$ cells/well. After $24 \mathrm{~h}$, the medium in the wells was replaced with fresh medium containing treatment agents as indicated. The plates were incubated at $37^{\circ} \mathrm{C}$ for the times indicated, with the medium being changed every 3 days. Following this, the medium was aspirated from each well, replaced with fresh RPMI medium containing MTT reagent $(0.5 \mathrm{mg} / \mathrm{ml})$ and incubated at $37^{\circ} \mathrm{C}$ for $4 \mathrm{~h}$. The MTT solution was gently aspirated form the wells prior to the addition of a solubilising reagent (1\% Triton X-100), and the plates were left at $4{ }^{\circ} \mathrm{C}$ overnight. The absorbance of the resulting solution was then read using a spectrophotometer $(\lambda 560 \mathrm{~nm})$.

Coulter counting assay For long-term ( $\geq 10$ days) growth experiments to study the combination effect of PF878 and trastuzumab on cell proliferation, Coulter counting was used as follows: following harvesting of cell lines by trypsinisation, viable cells were seeded at an initial density of $3 \times 10^{4} /$ well in 24 -well plates on day 0 . On day 1 , triplicate wells were trypsinised and the cells were counted using a Coulter Counter (Coulter Electronics Ltd., Luton, UK). In the remaining wells, the culture medium was aspirated and replaced with a medium containing treatment agents as indicated. Culture plates were then incubated for the times indicated prior to trypsinisation of the appropriate wells and counting of the cells using a Coulter Counter.

\section{Western blotting}

Log-phase cell cultures were lysed in $50 \mathrm{mM}$ Tris, $\mathrm{pH}$ 7.5, $5 \mathrm{mM}$ EGTA, $150 \mathrm{mM} \mathrm{NaCl}$ and $1 \%$ Triton X-100 containing protease inhibitors, $2 \mathrm{mM}$ sodium orthovanadate, $20 \mathrm{mM}$ sodium fluoride, $1 \mathrm{mM}$ phenylmethylsulphonyl fluoride, $20 \mu \mathrm{M}$ phenylarsine, $10 \mathrm{mM}$ sodium molybdate, $10 \mu \mathrm{g} / \mathrm{ml}$ leupeptin and $8 \mu \mathrm{g} / \mathrm{ml}$ aprotinin, and proteins were resolved by SDS-PAGE using $8 \%$ gels. The proteins were immobilised on nitrocellulose membranes and subsequently probed with antibodies that recognise the active forms of FAK and additional antibodies as stated in the Results section. Repeat immunoprobings were performed using panantibodies to determine the total levels of these proteins and GAPDH as a loading control. Western blots were then scanned to obtain data for semiquantitation with normalisation against GAPDH. Each experiment was performed at least three times with representative gels reported.

\section{Measurement of cell migration}

The cells were harvested and held in suspension in the presence of PF878 for $60 \mathrm{~min}$ prior to seeding onto fibronectin-coated polycarbonate, microporous membranes ( $8 \mu \mathrm{m}$ pore size) at $5 \times 10^{4}$ cells/membrane ( \pm heregulin (MDA-361 cells) or serum (BT-474 cells) as a chemoattractant added to the lower chamber) and allowed to migrate to the underside of the membranes for a period of $24 \mathrm{~h}$. Migratory cells were fixed, stained with $0.5 \%$ crystal violet and counted.

\section{Ki67 proliferation antigen staining}

Ki67 antigen was assessed in HER2 + BT-474 and MDA361 cells following treatment with trastuzumab \pm PF878 using MIB-1 anti-Ki67 antibodies (Coulter Electronics Ltd.). Briefly, the cells were grown and treated in petri dishes containing coverslips as indicated and then washed and fixed in formal saline. Primary antibodies (MIB-1) were applied to the coverslips after blocking with PBS/Tween, and incubation was carried out for 60 min. After washing with PBS, the secondary antibodies (Mouse Envision, DAKO UK Ltd., Ely, Cambridgeshire, UK) were applied to the coverslips for 75 min. After further washing with PBS, the chromogen ('SigmaFast' DAB, Sigma) was added to the cells for $10 \mathrm{~min}$, after which the coverslips were rinsed in distilled water. The samples were counterstained with 20\% haematoxylin for $3 \mathrm{~min}$ and mounted for examination by light microscopy. Control coverslips (no primary antibodies) were checked for non-specific binding before assessing staining intensity in the test samples. The percentage of Ki67-positive cells was calculated after counting at least 1000 tumour cells.

\section{Isobologram analysis}

An isobologram analysis was conducted as described by Menendez et al. (2007). To examine the interaction between trastuzumab and PF878, the cells were exposed to increasing concentrations of PF878 $(0-5 \mu \mathrm{M})$ and a range of concentrations $(0-10 \mu \mathrm{M})$ of trastuzumab to empirically determine the concentration of both agents necessary to achieve $30 \%$ inhibition $\left(\mathrm{IC}_{30}\right)$. The concentration of each agent that inhibited growth by $30 \%\left(\mathrm{IC}_{30}\right)$ was calculated and plotted on the separate axes of a graph; a straight line

Published by Bioscientifica Ltd. 
that joined these two points was then drawn, which represented the line of additivity (Steel \& Peckham 1979), i.e. zero interaction between two agents. Subsequently, growth assays were carried out using both agents in combination (PF878 $(0-5 \mu \mathrm{M})$ and trastuzumab $(0-10 \mu \mathrm{M}))$, and the data were examined to determine the concentrations of agents in combination that decreased cell proliferation by $30 \%$. These were then plotted on the graph. Where these experimental isoeffect points fall below the line of additivity, the combination effect of the two drugs is considered to be supra-additive or synergistic, whereas antagonism occurs if the point lies above it.

\section{Apoptosis analysis}

The cells were treated with PF878 $(1 \mu \mathrm{M})$, trastuzumab $(10 \mathrm{nM})$ or both agents in combination for either $2 \mathrm{~h}$ or 7 days, after which the cells were lysed and processed for western blotting as described above. Apoptosis was determined by immunoprobing using an antibody that recognises the cleaved form of poly(ADP-ribose) polymerase (PARP).

\section{Statistical analysis}

Data were analysed using two-tailed Student's $t$-test (cell migration and proliferation using PF878 as a single agent). One-way ANOVA with post hoc analysis was used in order to examine whether the inclusion of PF878 significantly affected the observations obtained with trastuzumab alone. Significance was assumed at $P<0.05$.

\section{Results}

\section{FAK activity is elevated in ER + /HER2 + vs ER + /HER2 - breast cancer cell lines}

The analysis of FAK expression and activity across a panel of four cell lines reflecting ER +/HER2 - (MCF7 and T47D) and ER +/HER2 + (BT-474 and MDA-361) breast cancer subtypes revealed that the levels of FAK per se were not changed between these cell lines (Fig. 1A). However, $\mathrm{ER}+/ \mathrm{HER} 2+$ cells displayed a non-significant trend for increased FAK activity (phosphorylation at Y861 but not at Y397). Interestingly, the extent of FAK phosphorylation at Y861 did not appear to correlate with the degree of intrinsic HER2 activity within the HER2-enriched cell lines, as the highest levels of FAK Y861 activity were observed in MDA-361 cells, which had the lowest HER2 activity within this cell subtype.

\section{ER + /HER2 + cell lines are more sensitive to PF878 vs ER + /HER2 - cells with respect to the inhibition of FAK phosphorylation at Y397}

The effects of the FAK-specific inhibitor PF878 on FAK phosphorylation at Y397 were subsequently examined; these data revealed that PF878 was able to suppress FAK Y397 activity in both ER +/HER2 - and ER +/HER2 + cell lines at sub-micromolar doses (Fig. 2). PF878 did not affect FAK phosphorylation at Y861 in T47D or BT-474 cells, but treatment did result in a partial loss of FAK Y861 activity in MCF7 and MDA-361 cells. The IC $_{50}$ values for FAK Y397 inhibition varied according to HER2 status, with both HER2-enriched cell lines demonstrating lower $\mathrm{IC}_{50}$ values vs HER2- cells (Table 1; $P<0.05$ for BT-474 vs MCF7 and T47D). Within the HER 2 + cell line group, BT-474 cells appeared to be more sensitive to PF878 with respect to the inhibition of FAK Y397 phosphorylation vs MDA-361 cells.

\section{Inhibition of FAK does not result in the suppression of FAK-related signalling pathway intermediates}

We next investigated whether the suppression of FAK activity by PF878 resulted in the inhibition of intracellular proteins implicated in FAK and/or HER2-mediated signalling. Studies were carried out using 24-h treatment samples to reveal sustained responses rather than transient ones to FAK inhibition and thus potentially reveal signalling pathways targeted by PF878 responsible for cell proliferation. No reduction in the levels of any of the FAK-related signalling molecules investigated was observed in the ER+/HER2 - MCF7 and T47D cells in response to PF878 with the exception of Akt (in MCF7 cells, Fig. 3A) and, to a much lesser extent, Src (in T47D cells, Fig. 3B).

The treatment of ER+/HER2 + BT-474 cells with PF878 again did not result in a significant suppression of FAK-related signalling, except for paxillin activity (Fig. 3C). In contrast to this, HER2 phosphorylation at Y1248 was observed to diminish in MDA-361 cells in a dose-dependent manner in response to PF878 (Fig. 3D), an effect that was not observed in BT-474 cells. Accompanying this was a reduction in the activity of Akt, Src and ERK1/2 (Fig. 3D).

\section{Inhibition of FAK suppresses breast cancer cell migration} but not proliferation

Given the potential role of FAK in the mediation of cellular behaviour downstream of growth factor receptor and

Published by Bioscientifica Ltd. 
A

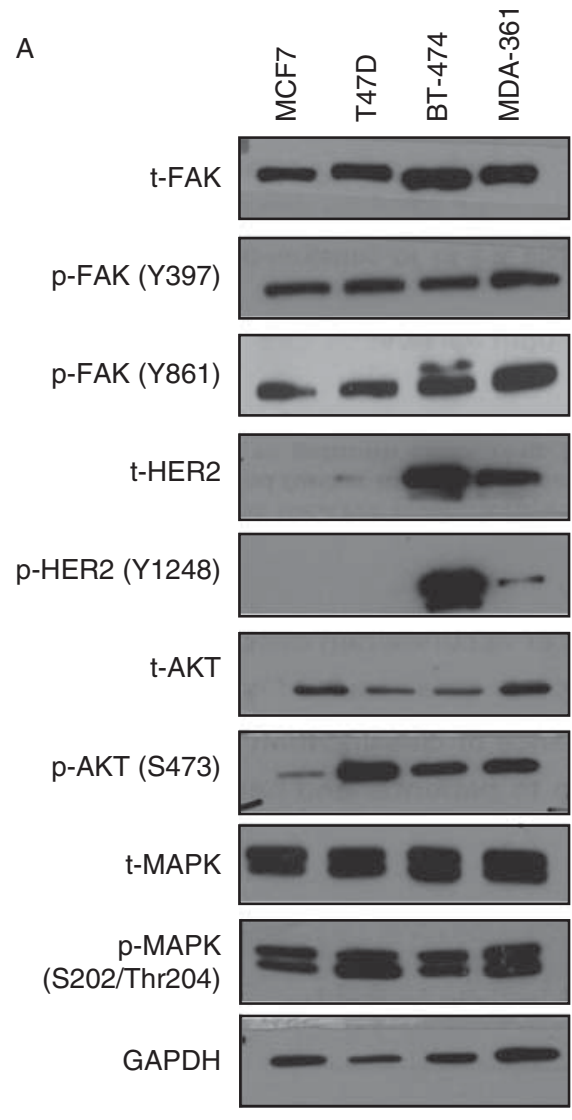

Figure 1

Expression and activity of FAK in ER +/HER2 - and ER +/HER2 + breast cancer cells. (A) Cellular lysates from ER+/HER2 - (MCF7 and T47D) and $\mathrm{ER}+/ \mathrm{HER} 2+(\mathrm{BT}-474$ and MDA-361) breast cancer cells grown under routine cell culture conditions as described in the Materials and methods section were immunoprobed for FAK, HER2 and signalling elements

integrin stimulation, we investigated whether the inhibition of FAK resulted in the suppression of cell proliferation. The inhibition of FAK using a range of doses of PF878 $(0-1 \mu \mathrm{M})$ that encompassed the $\mathrm{IC}_{50}$ for FAK phosphorylation at Y397 (Table 1) did not significantly affect the proliferation of any of the cell lines tested (Fig. 4A). Since FAK is downstream of integrins, we further investigated the hypothesis that FAK inhibition might result in greater effects in the presence of matrix components. However, the ability of PF878 to suppress the growth of BT-474 and MDA-361 cells growing on matrix (fibronectin)-coated surfaces was not significantly different from the results obtained using uncoated cell culture plates (Supplementary Figure 1, see section on supplementary data given at the end of this article).

Since FAK is well established as a key regulator of cell migration, we sought to further determine whether FAK inhibition affected the migration of these cell lines. All the
B
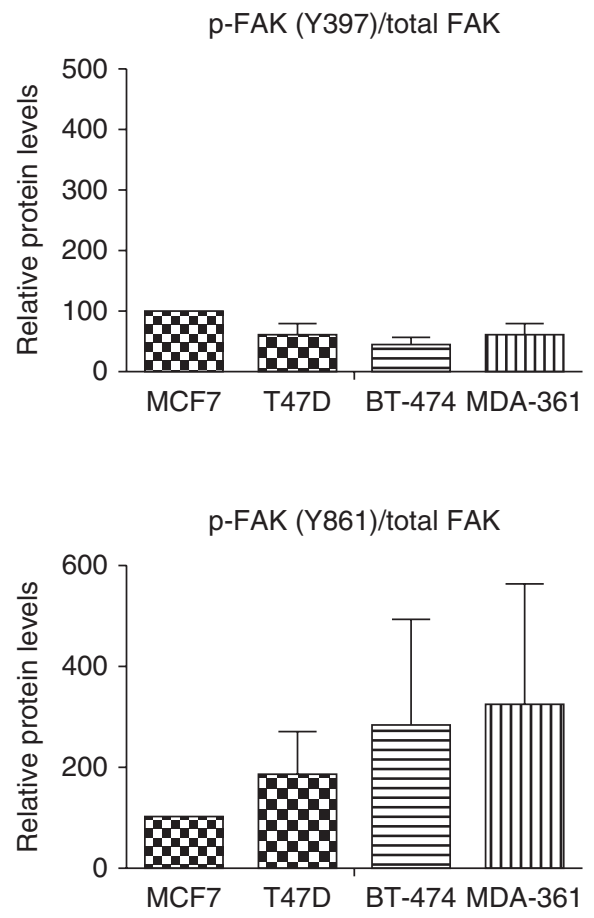

common to these pathways. (B) Densitometry showing the ratio of active:total p-FAK (Y397 and Y861) in all the four cell lines, normalised to GAPDH $(n=3)$, indicating that ER $+/$ HER2 + cell lines displayed increased FAK activation at Y861.

four cell lines exhibited very little intrinsic migratory capacity in Boyden chamber assays (data not shown), suggesting that any observed differences in endogenous FAK between these cells (Fig. 1) did not affect their intrinsic migratory nature. To further investigate the role of HER2 in migratory responses, we treated the ER +/HER2 + BT- 474 and MDA-361 cells with heregulin, a known activator of HER2-mediated signalling, and investigated the importance of FAK in this context. Heregulin stimulation greatly augmented the migratory capacity of MDA-361 cells, an effect that was antagonised by PF878 (Fig. 4B). Interestingly, heregulin treatment did not alter the migratory capacity of BT-474 cells over a range of concentrations tested $(0-100 \mathrm{ng} / \mathrm{ml})$, suggesting that HER2 signalling may not contribute to cell migration in these cells (data not shown). Despite a lack of response to heregulin, it has been previously shown that BT-474 cells can migrate in response to $20 \%$ serum (Worzfeld et al. 2012). Using serum as

Published by Bioscientifica Ltd. 


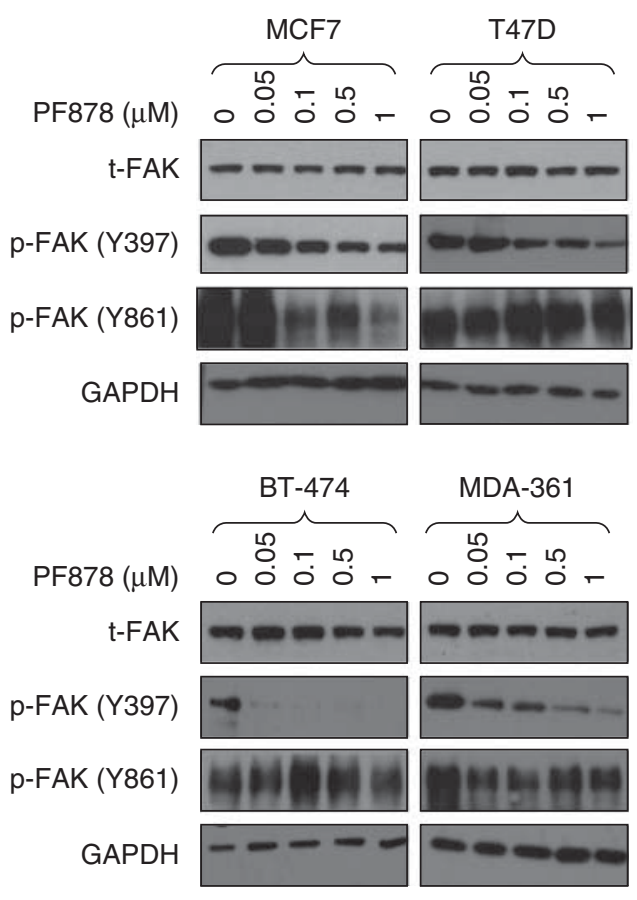

Figure 2

HER2 + cell lines are more sensitive to PF878 vs HER2 - cells. All four cell lines were treated with increasing concentrations of the FAK inhibitor PF878 for 60 min and immunoprobed for FAK (total and activated (Y397 and $\mathrm{Y} 861)$ ).

a chemoattractant in our assay, we were subsequently able to show that serum-induced migration of these cells could be significantly attenuated by PF878-mediated inhibition of FAK activity (Fig. 4C).

\section{Combined inhibition of FAK and HER2 in ER + /HER2 + breast cancer cells is synergistic towards the suppression of proliferation}

FAK is reported to function as an effector of erbB signalling, and our data (Fig. 2) suggested that ER+, HER2-enriched cells are more sensitive to FAK inhibition vs ER +/HER2cells. Although the inhibition of FAK activity alone did not affect the proliferation of ER+/HER $2+$ cells, we sought to investigate whether FAK inhibition was more effective when combined with the targeting of the HER2 receptor itself using trastuzumab.

The initial analysis of cell growth over a period of 10 days revealed that BT-474 cells were intrinsically sensitive to the growth suppressive effects of trastuzumab in contrast to MDA-361 cells, where trastuzumab treatment did not greatly affect cell proliferation (Fig. 5A). Subsequent treatment of these cell lines with trastuzumab in the presence of PF878 $(1 \mu \mathrm{M})$ revealed that the inclusion of PF878 resulted in a greater level of growth suppression than that observed when either was used as a single agent (Fig. $5 \mathrm{~B},{ }^{*} P<0.05$ ). This effect was particularly prevalent in MDA-361 cells, which appeared to be intrinsically resistant to trastuzumab alone (Fig. 5A). Further analysis of cell proliferation utilised immunocytochemical staining of the proliferation marker Ki67. These data again revealed that the number of actively proliferating cells was greatly reduced in cells treated with PF878 and trastuzumab in combination, an effect again more prevalent in MDA-361 cells (Fig. 5C).

To determine whether trastuzumab and PF878 were additive or synergistic, an isobologram analysis was carried out. First, the $\mathrm{IC}_{30}$ values for both agents alone were plotted (Fig. 6). After this, the concentrations of agents that, when combined, achieved the same level of growth suppression (i.e. 30\%) were added to the graph. The treatment of BT-474 and MDA-361 cells with PF878 and trastuzumab in combination was synergistic in suppressing the proliferation of these cells.

\section{PF878 and trastuzumab in combination suppress} signalling activity in ER + /HER2 + breast cancer cells and result in PARP cleavage

To explore potential mechanisms underlying the suggested synergistic inhibitory effect on ER +/HER2+ cell proliferation arising from co-targeting the HER2 receptor and FAK, western blotting was carried out for cells treated with PF878, trastuzumab or both agents in combination to reveal changes in key intracellular signalling components. Combination treatment resulted in a greater suppression of the phosphorylation of p-FAK (Y397), Akt (pS473) and MAPK (pS202/Thr204) in both cell lines after $24 \mathrm{~h}$ of treatment (Fig. 7A). In addition, PF878 appeared to prevent the increase in HER2 phosphorylation

Table $1 \quad I_{50}$ values for FAK inhibition (Y397) in ER + breast cancer cells according to HER2 status

\begin{tabular}{lllc} 
Cell line & $\begin{array}{l}\text { Breast cancer } \\
\text { molecular subtype }\end{array}$ & & $\begin{array}{c}\text { IC }_{50}(\mu \mathrm{M}), \text { FAK } \\
\text { inhibition (pY397) }\end{array}$ \\
\cline { 1 - 2 } & ER+, Her2 - & & $0.25 \pm 0.22$ \\
T47D & $E R+$, Her2 & & $0.26 \pm 0.39$ \\
BT-474 & ER+, Her2 & & $0.05 \pm 0.03$ \\
MDA-361 & ER,+ Her2 + & & $0.17 \pm 0.12$ \\
\hline
\end{tabular}

Densitometric analysis of the immunoblots of cells treated with PF878 was carried out and the IC $C_{50}$ values of PH878 were calculated ( $\mu \mathrm{M} \pm$ s.D.; data are the mean of at least three independent replicates). PF878 was more effective at inhibiting FAK phosphorylation at Y397 in ER +/HER2 + cell lines vs their HER2 counterparts.

Published by Bioscientifica Ltd. 
A

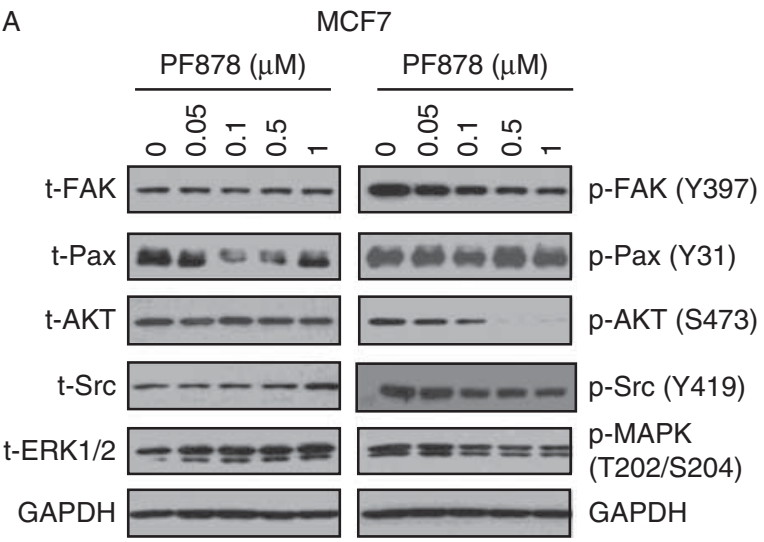

C

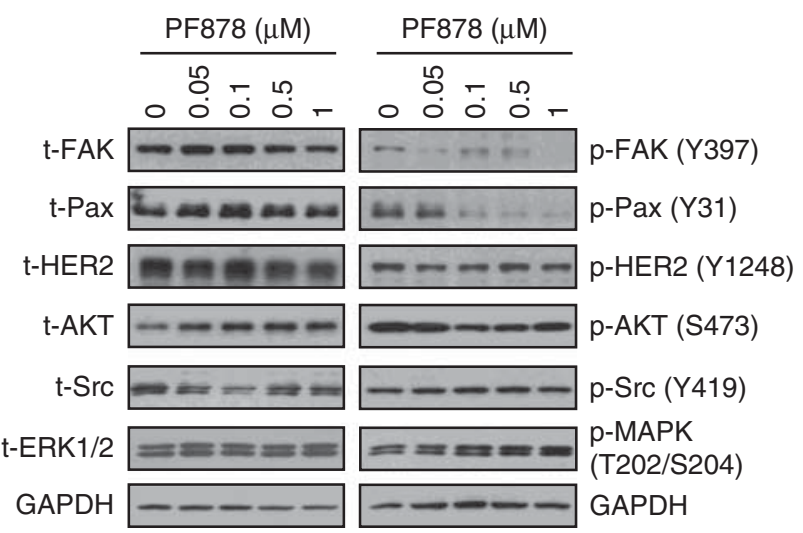

B

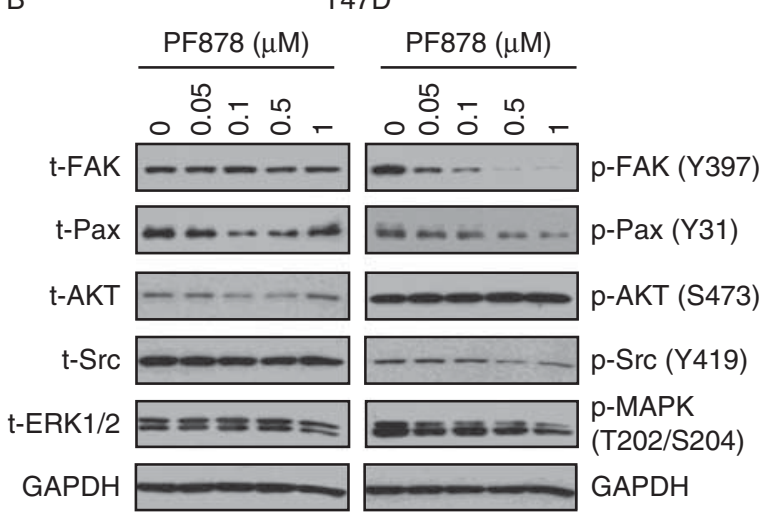

D

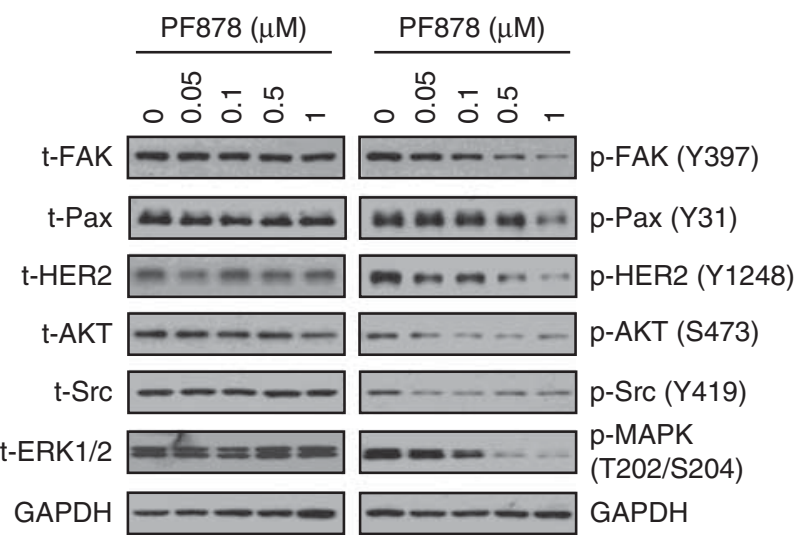

Figure 3

Inhibition of FAK activity suppresses endogenous FAK/HER2-related signalling in MDA-361 cells. All the four cell lines were treated with increasing concentrations of PF878 (0-1 $\mu \mathrm{M})$ for $60 \mathrm{~min}$, following which the cells were lysed and lysates were immunoprobed for the proteins

observed after trastuzumab treatment. While no effect was observed in cell-cycle progression (data not shown), analysis of PARP cleavage as a surrogate marker for apoptosis revealed that the combination treatment using PF878 and trastuzumab elevated the amount of the $23 \mathrm{kDa}$ PARP fragment detectable in the cell lysates (Fig. 7B).

\section{Discussion}

Breast cancer is known to represent a heterogeneous group of diseases possessing a wide spectrum of clinical, pathological and molecular characteristics with ER+ tumours accounting for around $70 \%$ of all cases diagnosed. A subset of ER+ tumours (around 10\%) is also enriched with the HER2 receptor (Bauer et al. 2010). Prior to the advent of anti-HER2 agents such as trastuzumab, patients with HER2 + disease had a poorer 5-year overall indicated. While there were limited effects of PF878 on FAK-related proteins in MCF7 (A), T47D (B) and BT-474 (C) cells, PF878 treatment of MDA-361 cells resulted in the inhibition of HER2, Akt, Src and ERK1/2 activity (D).

survival (Nguyen et al. 2008, Park et al. 2012). Interestingly, although the recent HERA trial points to a similar trastuzumab response irrespective of hormone receptor status (Untch et al. 2008), there is evidence that noeadjuvant trastuzumab may be less effective in $\mathrm{ER}+1$ HER2 + vs ER -/HER2 + tumours (Bhargava et al. 2011), suggesting that the presence of the ER in HER2 + tumours may be an important consideration. Conversely, the presence of HER2 in ER + tumours may also be a limiting factor for endocrine therapy, particularly since $\mathrm{ER}+1$ HER2 + tumours are likely to be treated with both endocrine and trastuzumab treatments. Moreover, while trastuzumab has shown clinical effectiveness in the treatment of HER $2+$ tumours (both ER + and ER-), its use is limited by resistance. Key to the development of improved therapies is the identification of molecular elements the targeting of which may have the potential

Published by Bioscientifica Ltd. 
A

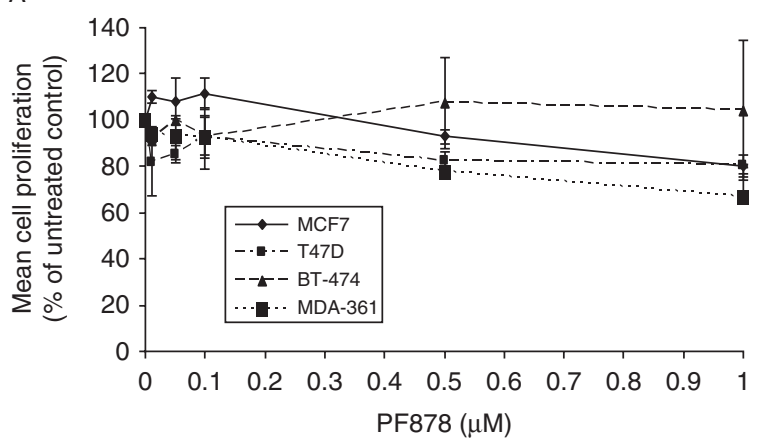

B

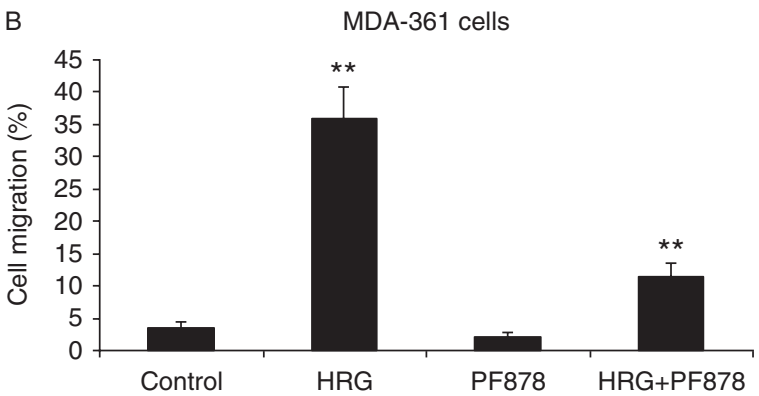

C

BT-474 cells

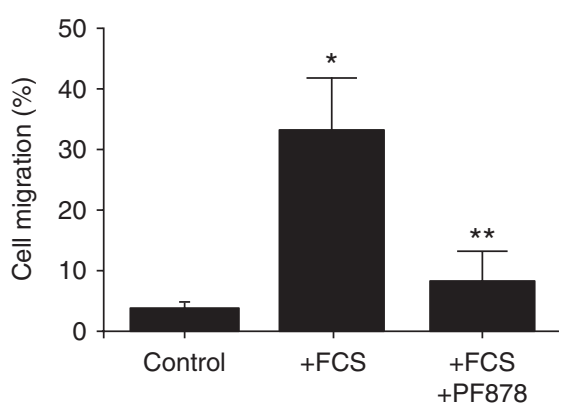

Figure 4

Inhibition of FAK activity does not affect ER +/HER2 + breast cancer cell proliferation but does suppresses heregulin- and serum-induced migration. (A) The growth of MCF7, T47D, BT-474 and MDA-361 cells in response to PF878 $(0-1 \mu \mathrm{M})$ over a period of 7 days was assessed using the MTT assay. Data are mean cell proliferation values \pm s.D. $(n=3)$. (B) The effects of PF878 $(1 \mu \mathrm{M})$ on heregulin-stimulated MDA-361 migration or (C) serum-induced migration of BT-474 cells were assessed using fibronectin-coated Boyden chambers. Data represent the mean numbers of migratory cells/field $(n=3)$. While FAK inhibition did not affect cell proliferation, PF878 was effective at preventing heregulin-induced migration of MDA-361 cells and seruminduced migration of BT-474 cells. MCF7 and T47D cells were not migratory either unstimulated or in response to heregulin (data not shown). ${ }^{*} P<0.05$ vs untreated cells and $* * P<0.05$ vs heregulin- or FCS-stimulated cells.

to augment the cellular response to anti-HER2 agents, particularly in the context of ER +/HER $2+$ tumours.

FAK is activated by HER2 (Nahta 2012) and can integrate signalling downstream of HER2 and other receptors resulting in the activation of the PI3K/Akt pathway (Nahta 2012). Both HER2 crosstalk and augmented PI3K/Akt signalling have been implicated in HER2 therapy resistance (Nahta 2012, Zhu et al. 2012), and FAK, through its involvement with HER2, is emerging as an important player in trastuzumab resistance (Wang et al. 2009, Yang et al. 2010). In this study, we set out to investigate the therapeutic potential of FAK in the context of ER +/HER2 + breast cancer.

Our initial observations revealed that there was no apparent correlation between endogenous HER2 status and FAK expression or its phosphorylation at Y397. However, the levels of FAK (Y861) appeared to be increased in the HER 2 + cells. Although some reports have suggested that elevated FAK expression is associated with HER2 overexpression (Lark et al. 2005, Schmitz et al. 2005), our data on FAK Y861 are in accordance with recent studies that have demonstrated higher levels of FAK Y861 expression to be associated with poor prognostic indicators including the overexpression and activation of HER-2 (Vadlamudi et al. 2002).

Importantly, both ER+/HER2 + cell lines demonstrated increased sensitivity to the FAK inhibitor vs ER +1 HER2 - cells; BT-474 cells, which had the highest degree of HER2 phosphorylation, demonstrated the greatest sensitivity to this compound. However, despite the effective suppression of FAK Y397, PF878 alone did not affect the proliferation of any of the cell lines. While PF878 concentrations $>5 \mu \mathrm{M}$ did elicit growth-inhibitory effects (data not shown), it is likely that these are due to off-target, FAK-independent effects, as has been reported to occur in other cell lines exposed to related FAK inhibitory compounds (Slack-Davis et al. 2007). Corresponding with the lack of significant growth inhibition, all cell lines showed a limited sensitivity to PF878 monotherapy in terms of the activation of other key growth-regulatory kinases (Akt, Src and MAPK). An exception to this was the MDA-361 cell line, in which PF878 suppressed Akt, Src, MAPK and HER2 phosphorylation. Although FAK inhibition may trigger an as-yet unidentified compensatory mechanism to sustain growth in the presence of reduced Akt and MAPK activity, a more obvious explanation for the observed discrepancy between the effects of PF878 on signalling and growth in these cells is that the residual signalling activity observed in the presence of PF878 is enough to sustain growth.

Coupled with a lack of evidence for growth inhibition, PF878 monotherapy had only a modest effect on the apoptotic profile of the cell lines tested here, as indicated by the minimal changes in PARP cleavage (Fig. 7). This was an initially surprising observation, given that FAK has been implicated as a pro-survival kinase and is able to

Published by Bioscientifica Ltd. 
A

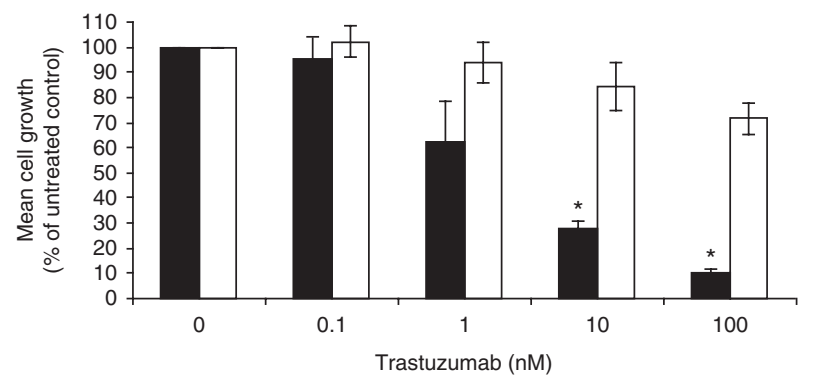

BT- 474

$\square$ MDA-36

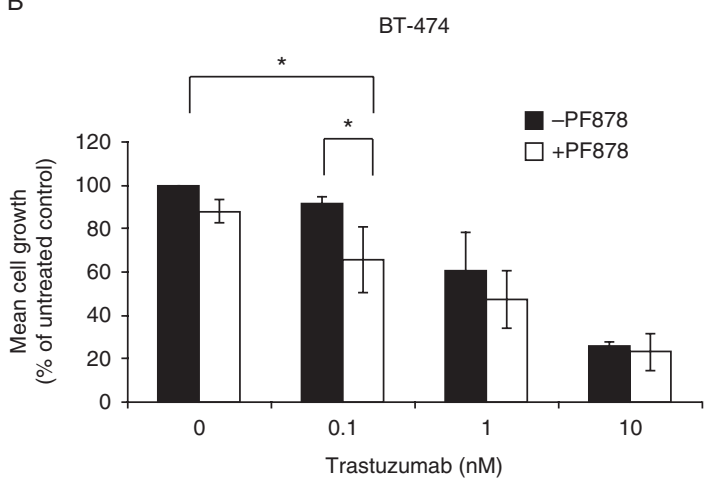

C
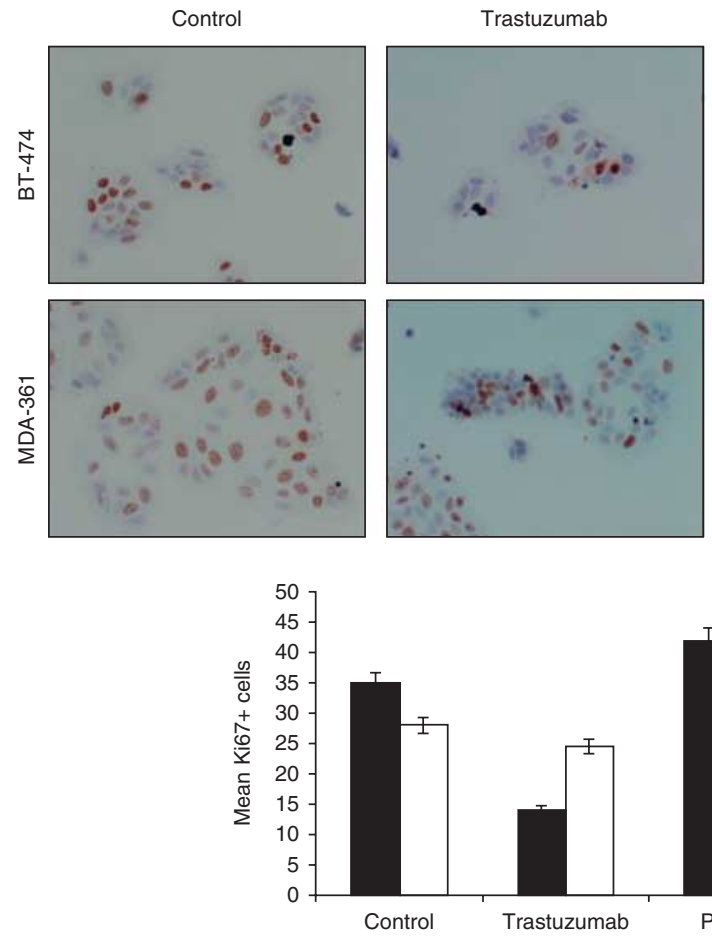

Figure 5

Targeting of FAK and HER2 together results in an improved suppression of HER2 + breast cancer cell proliferation vs monotherapy. (A) The ability of trastuzumab to antagonise the proliferation of HER2 + breast cancer cells was determined using the MTT assay. While BT-474 cells were growth inhibited by targeting the HER2 receptor, little effect was observed in MDA-361 cells. The anti-proliferative effects of PF878 and trastuzumab in combination on both cell lines were subsequently explored using Coulter
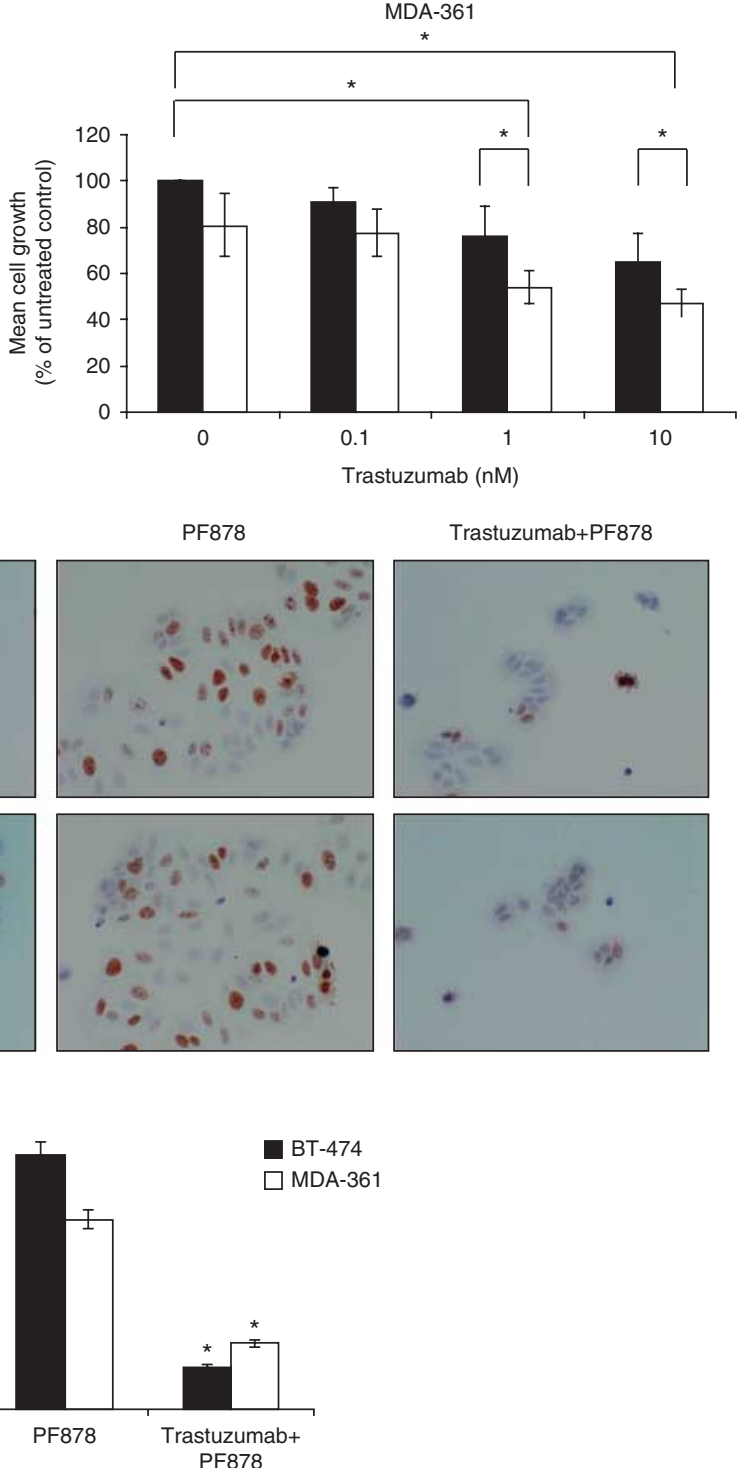

counting (B) and Ki67 immunocytochemistry; (C) the accompanying graph shows the mean proliferative cell counts (i.e. Ki67+) per field of view. These data revealed that the inhibition of FAK activity augmented trastuzumab-mediated growth suppression, an effect that was greatest in the trastuzumab-resistant MDA-361 cells. ${ }^{*} P<0.05$ vs single-agent treatments.

Published by Bioscientifica Ltd. 

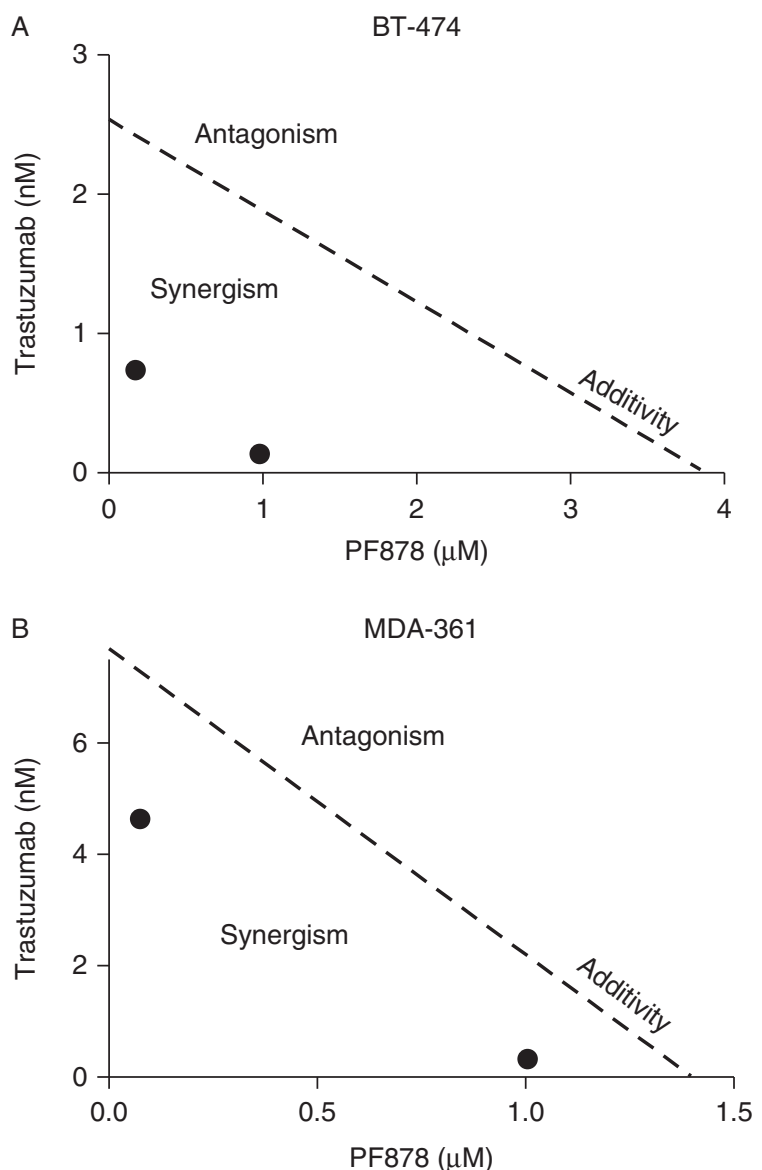

Figure 6

PF878 and trastuzumab are synergistic in suppressing ER +/HER2 + breast cancer cell proliferation. The nature of the interaction between PF878 and trastuzumab was evaluated using the isobologram technique, a doseoriented geometric method of assessing drug interactions. Using this approach, the concentrations of PF878 producing a desired effect (e.g. $30 \%$ inhibition of cell growth) were plotted in the vertical axis and the concentrations of trastuzumab producing the same growth-inhibitory effect were plotted on the horizontal axis. A straight line connecting these two points represents zero interaction between the two agents (i.e. additivity). Points were subsequently plotted for the concentrations of the two agents in combination that reduce cell proliferation by $30 \%$. Data points above the diagonal line of the additive effects in the isobole suggest antagonism, whereas points below the line suggest synergism. PF878 and trastuzumab in combination were synergistic at inhibiting the proliferation of both BT-474 (A) and MDA-361 (B) cells at all the drug concentrations tested.

down-regulate caspase expression (Kurenova et al. 2004). FAK-overexpressing cells also display resistance to apoptotic stimuli, while FAK inhibition has been shown to result in increased apoptosis (Smith et al. 2005). However, our data are supported by other reports that have failed to detect any clear change in apoptosis following siRNAmediated FAK knockdown (Han et al. 2004). Although these apparently conflicting data may simply reflect differences in the role of FAK in different tumour types, it is interesting to note that many studies in which FAK has been shown to suppress apoptosis have been carried out in $3 \mathrm{D}$ culture systems. This in turn points to the importance that the microenvironment has in FAK activity, where, for example, integrin-mediated FAK activation may promote pro-survival signalling. Such a hypothesis is supported by recent reports that pharmacological inhibition of FAK phosphorylation at Y397 using the FAK inhibitor PND1186 has no effect in 2D cell culture, but increases apoptosis in 3D culture (Tanjoni et al. 2010) and in vivo (Walsh et al. 2010).

In contrast to proliferative responses, the role of FAK in cell migration is widely established (reviewed in Mitra et al. (2005)), and many studies including the present study report that the inhibition of FAK activity suppresses breast cancer migration and invasion in vitro (Hiscox et al. 2011) and metastasis in vivo (Tanjoni et al. 2010). Interestingly, in contrast to MDA-361 cells, BT-474 cells were not responsive to the migration-promoting effects of heregulin. This may imply differential HER2 signalling between these cell types and may also explain the differential sensitivity of BT-474 and MDA-361 to trastuzumab. A further, and perhaps more significant explanation, is that these cell lines differ with respect to progesterone receptor (PR (PGR)) expression (S Hiscox, unpublished observations, 2012). This is important since ER + tumours that lack PG expression are known to be associated with a significantly poorer prognosis and a higher relapse frequency vs $\mathrm{ER}+/ \mathrm{PR}+$ tumours (Parise et al. 2009, Cancello et al. 2012). Although the exact molecular mechanisms underlying the potential importance of the PR in this context are unclear, it is interesting to note that only MDA-361 cells were able to migrate in response to heregulin stimulation, which may have bearing on HER 2 crosstalk with hormone receptors in these cells. These observations may allude to an increased aggressive behaviour in an in vivo context, where such cells would be exposed to growth factors within the tumour microenvironment.

Our data suggest a potentially important role for FAK in ER +/HER2 + tumours that exhibit reduced sensitivity to anti-HER2 agents, since PF878-mediated inhibition of FAK in trastuzumab-refractory MDA-361 cells resulted in a partial restoration of trastuzumab response, which may be linked to the increased suppression of Akt observed following combination treatment. Despite trastuzumab itself inhibiting Akt activity in both MDA-361 and BT-474 cells, only the latter were growth inhibited, suggesting that Akt is not part of the dominant growth-regulatory

Published by Bioscientifica Ltd. 
A

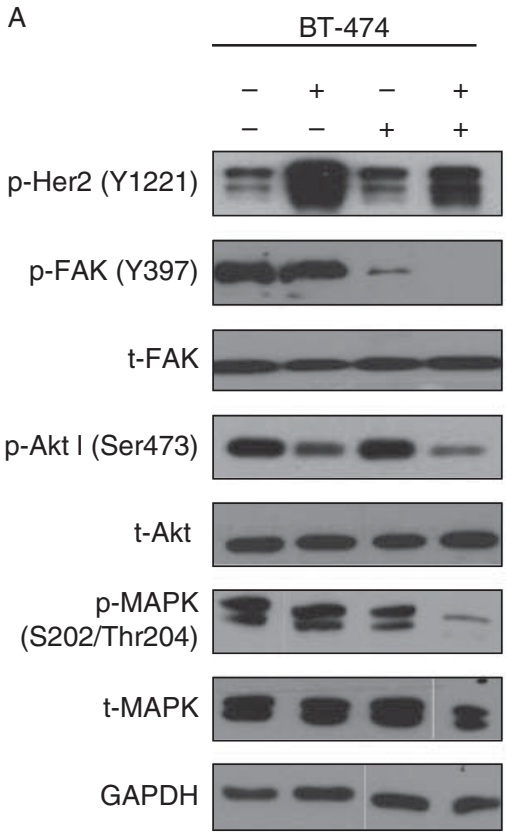

B

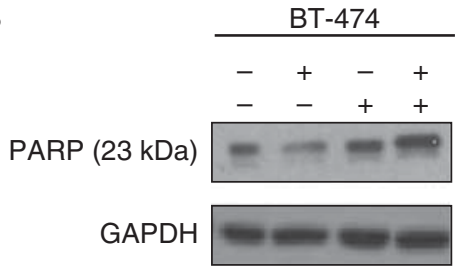

\section{Figure 7}

Combined targeting of FAK and HER2 in ER +/HER2 + breast cancer results in the suppression of intracellular signalling and PARP cleavage. BT-474 and MDA-361 cells were treated with PF878 $(1 \mu \mathrm{M})$, trastuzumab $(1 \mathrm{nM})$ or a combination of both the agents for $24 \mathrm{~h}$, and protein expression and activity were assessed by western blotting. (A) Co-targeting of FAK and

pathway in MDA-316 cells. However, there is also the possibility that HER2 heterodimerisation patterns in these cells might be different from those in trastuzumabsensitive BT-474 cells; this in turn might provide differential inputs into Akt regulation in these cell models, a hypothesis supported by Ghosh et al. (2011), who demonstrated that HER2 heterodimerisation can be associated with a lower response to trastuzumab. Alternatively, the residual Akt signalling (which is still substantial) observed in MDA-361 cells even after trastuzumab treatment may be enough to maintain cell proliferation, as is the case for PF878 monotherapy. Thus, combination treatment strategies such as PF878 and trastuzumab that better target the Akt pathway in Her2 + cells may hold promise for the treatment of such tumours, particularly in the context of limited trastuzumab sensitivity. Indeed, other reports have also shown
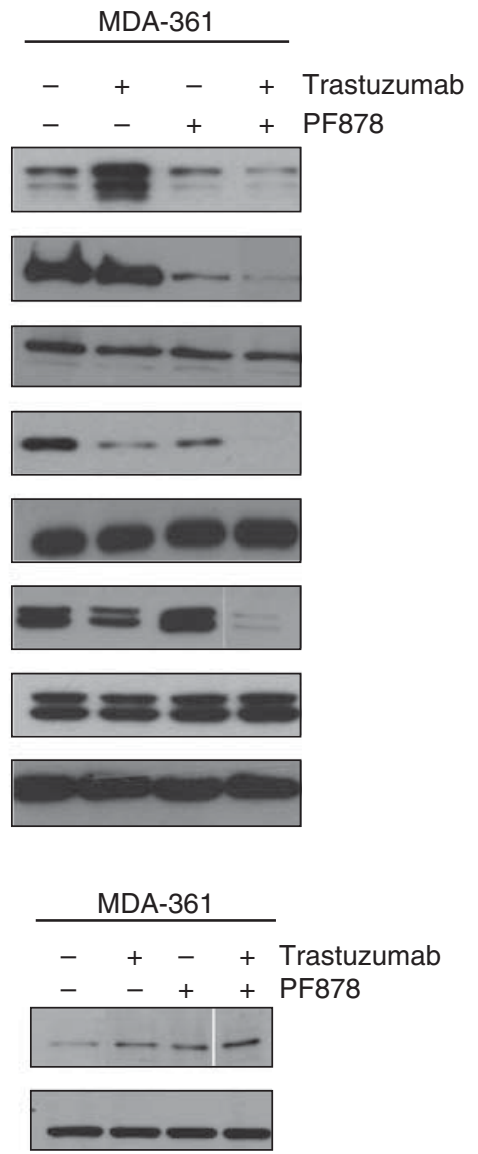

HER2 resulted in a greater suppression of FAK activity (Y397) and Akt and MAPK phosphorylation in both cell lines. (B) In lysates from cells subjected to both treatments in combination, there was also a greater amount of PARP cleavage products detectable.

that the combined targeting of the HER2 receptor is better than targeting using a single agent in terms of growth inhibition primarily because the levels of the suppression of the Akt signalling pathway are greater (Andre et al. 2008, Yao et al. 2009).

Interestingly, trastuzumab was observed to induce HER2 phosphorylation in both BT-474 and MDA-361 cells. Despite previous hypotheses that herceptin-based targeting of the HER2 receptor would inhibit HER2 signalling, recent studies have shown this not to be the case (Junttila et al. 2009) and have implicated ADAM17-mediated release of erbB ligands, arising through herceptinmediated $\mathrm{PKB}$ inhibition, as a potential mechanism to facilitate HER2 activation (Gijsen et al. 2010a,b). Since our experiments were carried out in the presence of serum (required to support long-term cell growth for the proliferation assays), this may represent a confounding

Published by Bioscientifica Ltd 
issue, although the endogenous signalling activity of HER2 and FAK and the levels of their downstream associated molecules were only modestly reduced in the absence of serum. Importantly, the effects of trastuzumab and PF878 under serum-reduced conditions were similar in terms of FAK and HER2 signalling. Our data further suggest that trastuzumab-augmented HER2 activity may involve FAK, since PF878 is able to suppress this phenomenon. Indeed, the failure of trastuzumab to suppress HER2 phosphorylation may represent one explanation as to the occurrence of acquired resistance to trastuzumab monotherapy and/or the presence of de novo insensitivity. In such settings, co-targeting other molecular elements such as FAK to suppress HER2 activity, as we demonstrated in BT- 474 cells, may provide benefits and overcome acquired resistance as has been suggested through combining trastuzumab with ADAM17 inhibitors (Gijsen et al. 2010b). While targeting FAK and HER2 together in trastuzumab-responsive BT-474 cells resulted in the suppression of HER2 activity, perhaps a more beneficial context is that of MDA-361 cells, where our data imply that co-targeting treatment strategies may also present an effective approach to the treatment of tumours with de novo trastuzumab resistance.

The use of FAK inhibitors in combination treatment regimens is further supported by recent studies showing that dual FAK and EGFR inhibition enhances apoptosis in breast cancer (Golubovskaya et al. 2002) and radiosensitivity in head and neck squamous-cell carcinomas (Eke \& Cordes 2011), the latter involving the suppression of the Akt and MEK pathways (Hehlgans et al. 2012). In pancreatic cancer models, pharmacological inhibition of both FAK and IGF1R decreases cell survival in vitro and leads to tumour regression in vivo (Zheng et al. 2010). Our data that PF878 and trastuzumab were synergistic in suppressing the proliferation of MDA-361 cells suggest that targeting FAK may also represent an important chemosensitisation strategy in resistant disease. This approach is supported by studies that have reported sensitisation to 5-fluorouracil (5-FU) and a partial reversion of 5-FU resistance when FAK is suppressed (Chen et al. 2009). Moreover, TAE226, a pharmacological inhibitor of FAK phosphorylation (Y397 and Y861), augments docetaxel sensitivity in taxane-resistant ovarian cancer cells (Halder et al. 2007). In such contexts, FAK may represent a convergence point for multiple signalling pathways that may contribute to resistance, highlighting its potential importance as a therapeutic target. Given that PF878 improved trastuzumab response in ER +/HER2 + cell, we further investigated whether FAK inhibition improved the treatment regimen of tamoxifen and trastuzumab in combination. While this dual treatment regimen was effective in trastuzumab-sensitive BT-474 cells, it did not offer significant benefits over tamoxifen alone in trastuzumab-insensitive MDA-361 cells. Importantly, inclusion of PF878 alongside tamoxifen and trastuzumab in combination resulted in a greater suppression of growth in both cell lines (Supplementary Figure 2, see section on supplementary data given at the end of this article), further implicating FAK as a potential therapeutic target in $\mathrm{ER}+/ \mathrm{HER} 2+$ tumours.

In conclusion, our data reported herein support a role for FAK in ER +/HER2 + breast cancer, where its targeting has the potential to improve trastuzumab response. This is particularly important in the context of trastuzumabrefractory disease, where FAK inhibition may present an important strategy to restore trastuzumab sensitivity.

\section{Supplementary data}

This is linked to the online version of the paper at http://dx.doi.org/10.1530/ ERC-13-0019.

\section{Declaration of interest}

The authors declare that there is no conflict of interest that could be perceived as prejudicing the impartiality of the research reported.

\section{Funding}

The authors thank Cancer Research Wales (PhD studentship, G Lazaro) and Pfizer (for provision of the FAK inhibitor, PF4554878 and support of L Goddard).

\section{References}

Andre F, Nahta R, Conforti R, Boulet T, Aziz M, Yuan LX, Meslin F, Spielmann M, Tomasic G, Pusztai L et al. 2008 Expression patterns and predictive value of phosphorylated AKT in early-stage breast cancer. Annals of Oncology 19 315-320. (doi:10.1093/annonc/mdm429)

Arribas J, Baselga J, Pedersen K \& Parra-Palau JL 2011 p95HER2 and breast cancer. Cancer Research 71 1515-1519. (doi:10.1158/0008-5472. CAN-10-3795)

Bauer K, Parise C \& Caggiano V 2010 Use of ER/PR/HER2 subtypes in conjunction with the 2007 St Gallen consensus statement for early breast cancer. BMC Cancer 10 228. (doi:10.1186/1471-2407-10-228)

Berns K, Horlings HM, Hennessy BT, Madiredjo M, Hijmans EM, Beelen K, Linn SC, Gonzalez-Angulo AM, Stemke-Hale K, Hauptmann M et al. 2007 A functional genetic approach identifies the PI3K pathway as a major determinant of trastuzumab resistance in breast cancer. Cancer Cell 12 395-402. (doi:10.1016/j.ccr.2007.08.030)

Bhargava R, Dabbs DJ, Beriwal S, Yildiz IA, Badve P, Soran A, Johnson RR, Brufsky AM, Lembersky BC, McGuire KP et al. 2011 Semiquantitative hormone receptor level influences response to trastuzumab-containing neoadjuvant chemotherapy in HER2-positive breast cancer. Modern Pathology 24 367-374. (doi:10.1038/modpathol.2010.209) http://erc.endocrinology-journals.org DOI: 10.1530/ERC-13-0019
(C) 2013 Society for Endocrinology Printed in Great Britain 
Cancello G, Maisonneuve P, Rotmensz N, Viale G, Mastropasqua MG, Pruneri G, Montagna E, Iorfida M, Mazza M, Balduzzi A et al. 2012 Progesterone receptor loss identifies luminal B breast cancer subgroups at higher risk of relapse. Annals of Oncology 24 661-668. (doi:10.1093/ annonc/mds430)

Carter P, Presta L, Gorman CM, Ridgway JB, Henner D, Wong WL, Rowland AM, Kotts C, Carver ME \& Shepard HM 1992 Humanization of an anti-p185HER2 antibody for human cancer therapy. PNAS $\mathbf{8 9}$ 4285-4289. (doi:10.1073/pnas.89.10.4285)

Chen YY, Wang ZX, Chang PA, Li JJ, Pan F, Yang L, Bian ZH, Zou L, He JM \& Liang HJ 2009 Knockdown of focal adhesion kinase reverses colon carcinoma multicellular resistance. Cancer Science 100 1708-1713. (doi:10.1111/j.1349-7006.2009.01217.x)

Cicchini C, Laudadio I, Citarella F, Corazzari M, Steindler C, Conigliaro A, Fantoni A, Amicone L \& Tripodi M 2008 TGF $\beta$-induced EMT requires focal adhesion kinase (FAK) signaling. Experimental Cell Research $\mathbf{3 1 4}$ 143-152. (doi:10.1016/j.yexcr.2007.09.005)

Eke I \& Cordes N 2011 Dual targeting of EGFR and focal adhesion kinase in 3D grown HNSCC cell cultures. Radiotherapy and Oncology 99 279-286. (doi:10.1016/j.radonc.2011.06.006)

Ghosh R, Narasanna A, Wang SE, Liu S, Chakrabarty A, Balko JM, Gonzalez-Angulo AM, Mills GB, Penuel E, Winslow J et al. 2011 Trastuzumab has preferential activity against breast cancers driven by HER2 homodimers. Cancer Research 71 1871-1882. (doi:10.1158/00085472.CAN-10-1872)

Gijsen M, King P, Perera T, Parker P, Larijani B, Harris A \& Kong A 2010a Upregulation of ADAM proteases and HER ligands through a feedback loop mediates acquired resistance to trastuzumab in HER2-amplified breast cancer. Breast Cancer Research 12 (Suppl 1) O2. (doi:10.1186/ bcr2493)

Gijsen M, King P, Perera T, Parker PJ, Harris AL, Larijani B \& Kong A $2010 b$ HER2 phosphorylation is maintained by a PKB negative feedback loop in response to anti-HER2 herceptin in breast cancer. PLoS Biology $\mathbf{8}$ e1000563. (doi:10.1371/journal.pbio.1000563)

Golubovskaya V, Beviglia L, Xu LH, Earp HS III, Craven R \& Cance W 2002 Dual inhibition of focal adhesion kinase and epidermal growth factor receptor pathways cooperatively induces death receptor-mediated apoptosis in human breast cancer cells. Journal of Biological Chemistry 277 38978-38987. (doi:10.1074/jbc.M205002200)

Guiu S, Michiels S, Andre F, Cortes J, Denkert C, Di Leo A, Hennessy BT, Sorlie T, Sotiriou C, Turner N et al. 2012 Molecular subclasses of breast cancer: how do we define them? The IMPAKT 2012 Working Group Statement Annals of Oncology 23 2997-3006. (doi:10.1093/annonc/mds586)

Halder J, Lin YG, Merritt WM, Spannuth WA, Nick AM, Honda T, Kamat AA, Han LY, Kim TJ, Lu C et al. 2007 Therapeutic efficacy of a novel focal adhesion kinase inhibitor TAE226 in ovarian carcinoma. Cancer Research 67 10976-10983. (doi:10.1158/0008-5472.CAN-07-2667)

Han EK, McGonigal T, Wang J, Giranda VL \& Luo Y 2004 Functional analysis of focal adhesion kinase (FAK) reduction by small inhibitory RNAs. Anticancer Research 24 3899-3905.

Haque R, Ahmed SA, Inzhakova G, Shi J, Avila C, Polikoff J, Bernstein L, Enger SM \& Press MF 2012 Impact of breast cancer subtypes and treatment on survival: an analysis spanning two decades. Cancer Epidemiology, Biomarkers \& Prevention 21 1848-1855. (doi:10.1158/ 1055-9965.EPI-12-0474)

Hehlgans S, Eke I \& Cordes N 2012 Targeting FAK radiosensitizes 3-dimensional grown human HNSCC cells through reduced Akt1 and MEK1/2 signaling. International Journal of Radiation Oncology, Biology, Physics 83 e669-e676. (doi:10.1016/j.ijrobp.2012.01.065)

Hiscox S, Barnfather P, Hayes E, Bramble P, Christensen J, Nicholson RI \& Barrett-Lee P 2011 Inhibition of focal adhesion kinase suppresses the adverse phenotype of endocrine-resistant breast cancer cells and improves endocrine response in endocrine-sensitive cells. Breast Cancer Research and Treatment 125 659-669. (doi:10.1007/s10549-010-0857-4)
Hynes NE, Gerber HA, Saurer S \& Groner B 1989 Overexpression of the c-erbB-2 protein in human breast tumor cell lines. Journal of Cellular Biochemistry 39 167-173. (doi:10.1002/jcb.240390208)

Infante JR, Camidge DR, Mileshkin LR, Chen EX, Hicks RJ, Rischin D, Fingert H, Pierce KJ, Xu H, Roberts WG et al. 2012 Safety, pharmacokinetic, and pharmacodynamic phase I dose-escalation trial of PF-00562271, an inhibitor of focal adhesion kinase, in advanced solid tumors. Journal of Clinical Oncology 30 1527-1533. (doi:10.1200/ JCO.2011.38.9346)

Ishitobi M, Okumura Y, Arima N, Yoshida A, Nakatsukasa K, Iwase T, Shien T, Masuda N, Tanaka S, Tanabe M et al. 2013 Breast cancer subtype and distant recurrence after ipsilateral breast tumor recurrence. Annals of Surgical Oncology 20 1886-1892. (doi:10.1245/s10434-012-2825-1)

Itoh S, Maeda T, Shimada M, Aishima S, Shirabe K, Tanaka S \& Maehara Y 2004 Role of expression of focal adhesion kinase in progression of hepatocellular carcinoma. Clinical Cancer Research 10 2812-2817. (doi:10.1158/1078-0432.CCR-1046-03)

Junttila TT, Akita RW, Parsons K, Fields C, Lewis Phillips GD, Friedman LS Sampath D \& Sliwkowski MX 2009 Ligand-independent HER2/HER3/ PI3K complex is disrupted by trastuzumab and is effectively inhibited by the PI3K inhibitor GDC-0941. Cancer Cell 15 429-440. (doi:10.1016/ j.ccr.2009.03.020)

Kurenova E, Xu LH, Yang X, Baldwin AS Jr, Craven RJ, Hanks SK, Liu ZG \& Cance WG 2004 Focal adhesion kinase suppresses apoptosis by binding to the death domain of receptor-interacting protein. Molecular and Cellular Biology 24 4361-4371. (doi:10.1128/MCB.24.10.4361-4371.2004)

Lark AL, Livasy CA, Dressler L, Moore DT, Millikan RC, Geradts J, Iacocca M, Cowan D, Little D, Craven RJ et al. 2005 High focal adhesion kinase expression in invasive breast carcinomas is associated with an aggressive phenotype. Modern Pathology 18 1289-1294. (doi:10.1038/modpathol. 3800424)

Lee-Hoeflich ST, Crocker L, Yao E, Pham T, Munroe X, Hoeflich KP, Sliwkowski MX \& Stern HM 2008 A central role for HER3 in HER2-amplified breast cancer: implications for targeted therapy. Cancer Research 68 5878-5887. (doi:10.1158/0008-5472.CAN-08-0380)

Lin HJ, Hsieh FC, Song H \& Lin J 2005 Elevated phosphorylation and activation of PDK-1/AKT pathway in human breast cancer. British Journal of Cancer 93 1372-1381. (doi:10.1038/sj.bjc.6602862)

Menendez JA, Vazquez-Martin A, Colomer R, Brunet J, Carrasco-Pancorbo A Garcia-Villalba R, Fernandez-Gutierrez A \& Segura-Carretero A 2007 Olive oil's bitter principle reverses acquired autoresistance to trastuzumab (Herceptin $^{\mathrm{TM}}$ ) in HER2-overexpressing breast cancer cells. BMC Cancer $\mathbf{7}$ 80. (doi:10.1186/1471-2407-7-80)

Millar EK, Graham PH, O’Toole SA, McNeil CM, Browne L, Morey AL, Eggleton S, Beretov J, Theocharous C, Capp A et al. 2009 Prediction of local recurrence, distant metastases, and death after breast-conserving therapy in early-stage invasive breast cancer using a five-biomarker panel. Journal of Clinical Oncology 27 4701-4708. (doi:10.1200/JCO. 2008.21.7075)

Mitra SK, Hanson DA \& Schlaepfer DD 2005 Focal adhesion kinase: in command and control of cell motility. Nature Reviews. Molecular Cell Biology 6 56-68. (doi:10.1038/nrm1549)

Nahta R 2012 Pharmacological strategies to overcome HER2 cross-talk and trastuzumab resistance. Current Medicinal Chemistry 19 1065-1075. (doi:10.2174/092986712799320691)

Nguyen PL, Taghian AG, Katz MS, Niemierko A, Abi Raad RF, Boon WL, Bellon JR, Wong JS, Smith BL \& Harris JR 2008 Breast cancer subtype approximated by estrogen receptor, progesterone receptor, and HER-2 is associated with local and distant recurrence after breast-conserving therapy. Journal of Clinical Oncology 26 2373-2378. (doi:10.1200/JCO. 2007.14.4287)

Parise CA, Bauer KR, Brown MM \& Caggiano V 2009 Breast cancer subtypes as defined by the estrogen receptor (ER), progesterone receptor (PR), and the human epidermal growth factor receptor 2 (HER2) among women with invasive breast cancer in California, 1999-2004. Breast Journal 15 593-602. (doi:10.1111/j.1524-4741.2009.00822.x) http://erc.endocrinology-journals.org

DOI: 10.1530/ERC-13-0019
(C) 2013 Society for Endocrinology Printed in Great Britain 
Park S, Koo JS, Kim MS, Park HS, Lee JS, Kim SI \& Park BW 2012 Characteristics and outcomes according to molecular subtypes of breast cancer as classified by a panel of four biomarkers using immunohistochemistry. Breast 21 50-57. (doi:10.1016/j.breast.2011.07.008)

Ponnusamy MP, Singh AP, Jain M, Chakraborty S, Moniaux N \& Batra SK 2008 MUC4 activates HER2 signalling and enhances the motility of human ovarian cancer cells. British Journal of Cancer 99 520-526. (doi:10.1038/sj.bjc.6604517)

Romond EH, Perez EA, Bryant J, Suman VJ, Geyer CE Jr, Davidson NE, Tan-Chiu E, Martino S, Paik S, Kaufman PA et al. 2005 Trastuzumab plus adjuvant chemotherapy for operable HER2-positive breast cancer. New England Journal of Medicine 353 1673-1684. (doi:10.1056/NEJMoa052122)

Schmitz KJ, Grabellus F, Callies R, Otterbach F, Wohlschlaeger J, Levkau B, Kimmig R, Schmid KW \& Baba HA 2005 High expression of focal adhesion kinase (p125FAK) in node-negative breast cancer is related to overexpression of HER-2/neu and activated Akt kinase but does not predict outcome. Breast Cancer Research 7 R194-R203. (doi:10.1186/bcr977)

Sieg DJ, Hauck CR, Ilic D, Klingbeil CK, Schaefer E, Damsky CH \& Schlaepfer DD 2000 FAK integrates growth-factor and integrin signals to promote cell migration. Nature Cell Biology 2 249-256. (doi:10.1038/ 35010517)

Slack-Davis JK, Martin KH, Tilghman RW, Iwanicki M, Ung EJ, Autry C, Luzzio MJ, Cooper B, Kath JC, Roberts WG et al. 2007 Cellular characterization of a novel focal adhesion kinase inhibitor. Journal of Biological Chemistry 282 14845-14852. (doi:10.1074/jbc.M606695200)

Smith CS, Golubovskaya VM, Peck E, Xu LH, Monia BP, Yang X \& Cance WG 2005 Effect of focal adhesion kinase (FAK) downregulation with FAK antisense oligonucleotides and 5-fluorouracil on the viability of melanoma cell lines. Melanoma Research 15 357-362. (doi:10.1097/ 00008390-200510000-00003)

Steel GG \& Peckham MJ 1979 Exploitable mechanisms in combined radiotherapy-chemotherapy: the concept of additivity. International Journal of Radiation Oncology, Biology, Physics 5 85-91. (doi:10.1016/ 0360-3016(79)90044-0)

Tanjoni I, Walsh C, Uryu S, Tomar A, Nam JO, Mielgo A, Lim ST, Liang C, Koenig M, Sun C et al. 2010 PND-1186 FAK inhibitor selectively promotes tumor cell apoptosis in three-dimensional environments. Cancer Biology \& Therapy 9 764-777. (doi:10.4161/cbt.9.10.11434)

Untch M, Gelber RD, Jackisch C, Procter M, Baselga J, Bell R, Cameron D, Bari M, Smith I, Leyland-Jones B et al. 2008 Estimating the magnitude of trastuzumab effects within patient subgroups in the HERA trial. Annals of Oncology 19 1090-1096. (doi:10.1093/annonc/mdn005)

Vadlamudi RK, Adam L, Nguyen D, Santos M \& Kumar R 2002 Differential regulation of components of the focal adhesion complex by heregulin: role of phosphatase SHP-2. Journal of Cellular Physiology 190 189-199. (doi:10.1002/jcp.10054)

Vadlamudi RK, Sahin AA, Adam L, Wang RA \& Kumar R 2003 Heregulin and HER2 signaling selectively activates c-Src phosphorylation at tyrosine 215. FEBS Letters 543 76-80. (doi:10.1016/S00145793(03)00404-6)

Vogel CL, Cobleigh MA, Tripathy D, Gutheil JC, Harris LN, Fehrenbacher L, Slamon DJ, Murphy M, Novotny WF, Burchmore M et al. 2002 Efficacy and safety of trastuzumab as a single agent in first-line treatment of HER2-overexpressing metastatic breast cancer. Journal of Clinical Oncology 20 719-726. (doi:10.1200/JCO.20.3.719)

Walsh C, Tanjoni I, Uryu S, Tomar A, Nam JO, Luo H, Phillips A, Patel N, Kwok C, McMahon G et al. 2010 Oral delivery of PND-1186 FAK inhibitor decreases tumor growth and spontaneous breast to lung metastasis in pre-clinical models. Cancer Biology \& Therapy 9 778-790. (doi:10.4161/cbt.9.10.11433)

Wang SE, Wu FY, Shin I, Qu S \& Arteaga CL 2005 Transforming growth factor $\{\beta\}$ (TGF- $\{\beta\})$-Smad target gene protein tyrosine phosphatase receptor type $\kappa$ is required for TGF- $\{\beta\}$ function. Molecular and Cellular Biology 25 4703-4715. (doi:10.1128/MCB.25.11.4703-4715.2005)

Wang SE, Xiang B, Zent R, Quaranta V, Pozzi A \& Arteaga CL 2009 Transforming growth factor $\beta$ induces clustering of HER2 and integrins by activating Src-focal adhesion kinase and receptor association to the cytoskeleton. Cancer Research 69 475-482. (doi:10.1158/0008-5472. CAN-08-2649)

Worzfeld T, Swiercz JM, Looso M, Straub BK, Sivaraj KK \& Offermanns S 2012 ErbB-2 signals through Plexin-B1 to promote breast cancer metastasis. Journal of Clinical Investigation 122 1296-1305. (doi:10.1172/JCI60568)

Yang XH, Flores LM, Li Q, Zhou P, Xu F, Krop IE \& Hemler ME 2010 Disruption of laminin-integrin-CD151-focal adhesion kinase axis sensitizes breast cancer cells to ErbB2 antagonists. Cancer Research 70 2256-2263. (doi:10.1158/0008-5472.CAN-09-4032)

Yao E, Zhou W, Lee-Hoeflich ST, Truong T, Haverty PM, Eastham-Anderson J, Lewin-Koh N, Gunter B, Belvin M, Murray LJ et al. 2009 Suppression of HER2/HER3-mediated growth of breast cancer cells with combinations of GDC-0941 PI3K inhibitor, trastuzumab, and pertuzumab. Clinical Cancer Research 15 4147-4156. (doi:10.1158/1078-0432.CCR-08-2814)

Zheng D, Golubovskaya V, Kurenova E, Wood C, Massoll NA, Ostrov D, Cance WG \& Hochwald SN 2010 A novel strategy to inhibit FAK and IGF-1R decreases growth of pancreatic cancer xenografts. Molecular Carcinogenesis 49 200-209.

Zhu Y, Zhang X, Liu Y, Zhang S, Liu J, Ma Y \& Zhang J 2012 Antitumor effect of the mTOR inhibitor everolimus in combination with trastuzumab on human breast cancer stem cells in vitro and in vivo. Tumor Biology.

Received in final form 29 July 2013

Accepted 30 July 2013

Made available online as an Accepted Preprint 30 July 2013
(C) 2013 Society for Endocrinology Printed in Great Britain
Published by Bioscientifica Ltd. 